\title{
Highly efficient adsorption of hexavalent chromium from the aqueous system using nanoporous carbon modified with tetraethylenepentamine
}

\author{
A. Ghaffari - S. W. Husain - M. S. Tehrani · \\ M. Anbia - P. A. Azar
}

Received: 10 March 2014/Revised: 13 November 2014/Accepted: 7 December 2014/Published online: 23 December 2014

(C) Islamic Azad University (IAU) 2014

\begin{abstract}
An oxidized mesoporous carbon material, modified with tetraethylenepentamine, has been developed as a highly efficient adsorbent for hexavalent chromium. Influence of parameters such as adsorbent dose (0.1-0.8 $\left.\mathrm{g} \mathrm{L}^{-1}\right)$ solution $\mathrm{pH}(1-9)$, contact time, and initial concentration (100-1,000 $\mathrm{mg} \mathrm{L}^{-1}$ ) on adsorption capacity has been investigated and optimized. The sorption equilibrium was reached within $60 \mathrm{~min}$. The structural order and textural properties of the synthesized material were studied by X-ray diffraction, scanning electron microscopy, Fourier transform infrared, and nitrogen adsorptiondesorption analysis. The experimental results were analyzed by the Langmuir and Freundlich isotherms. The maximum adsorption capacity of $510 \mathrm{mg} \mathrm{g}^{-1}$ at an initial concentration of $1,000 \mathrm{mg} \mathrm{L}^{-1}$ is well predicted by the Freundlich isotherm. The kinetic analysis indicated that the adsorption process was successfully fitted with the pseudofirst-order kinetic model. Compared to other adsorbents reported in the literature, the modified nanoporous carbon material prepared in this study is found to be highly efficient adsorbent for the removal of hexavalent chromium from wastewater.
\end{abstract}

Keywords Adsorption isotherm · Hexavalent chromium · Mesoporous carbon adsorbent - Tetraethylenepentamine

A. Ghaffari $(\bowtie) \cdot$ S. W. Husain - M. S. Tehrani · P. A. Azar Department of Chemistry, Science and Research Branch, Islamic Azad University, Poonak-Hesarak, Tehran, Iran

e-mail: arezoghafari@yahoo.com

M. Anbia

Research Laboratory of Nanoporous Materials, Faculty of Chemistry, Iran University of Science and Technology, Farjam Street, Narmak, 16846 Tehran, Iran

\section{Introduction}

Environmental pollution, because of the release of toxic compound, especially heavy metals by industries in the environment and waters, has attracted much concern in recent years. The rapid development of leather tanning, dye and pigment, electroplating, metallurgy, refractory materials, and catalysts has resulted in increase in chromium contamination of water streams and has become a very serious problem (Zhao et al. 2013). In the aqueous environments, chromium exists in hexavalent and trivalent forms. Hexavalent chromium exists as highly toxic chromate ions $\left(\mathrm{HCrO}_{4}^{-1}\right.$ or $\left.\mathrm{Cr}_{2} \mathrm{O}_{7}^{-2}\right)$ and extremely soluble which can freely enter in the aquatic environment (Mitra et al. 2011). Persistent exposure to $\mathrm{Cr}(\mathrm{VI})$ causes health problems like hemorrhage, skin dermatitis, severe diarrhea, bronchitis, and perforation of the nasal septum (Deng and Alan 1996; Ai et al. 2008). Therefore, it is essential to remove $\mathrm{Cr}(\mathrm{VI})$ from wastewater before disposal. The limit of $\mathrm{Cr}(\mathrm{VI})$ in drinking water proposed by the US EPA is $0.05 \mathrm{mg} \mathrm{L}^{-1}$, while the maximum limit is $0.10 \mathrm{~m} \mathrm{~L} \mathrm{~L}^{-1}$ in industrial wastewater (Wang et al. 2010). Various technologies have been used to remove $\mathrm{Cr}(\mathrm{VI})$ from wastewater including chemical precipitation, ion exchange, chemical reduction, electrocoagulation, membranes (reverse osmosis, nanofiltration, and ultrafiltration), adsorption, and biological processes (Alidokht et al. 2011; Bhatti et al. 2009; Olmez 2009; Diaz et al. 2012; Yoon et al. 2009; Liu et al. 2012). Out of these methods, adsorption draws higher attention due to its low cost, simple operation, and high efficiency. Consequently, it is important to develop effective adsorbents with short adsorption equilibrium time for the removal of toxic compounds from aqueous solutions. Recent researches show that mesoporous materials (Anbia and Mohammadi 
2009a, b; Anbia and Mandegarzad 2012; Anbia and Ghaffari 2009; Anbia et al. 2006) can have good selectivity, large adsorption capacity, and improved recoverability for the removal of toxic species from aqueous solutions. Ordered mesoporous materials such as MCM48, SBA-15, MCM-41, CMK-1, and CMK-3 have attracted much attention owing to their special properties, such as regular framework, high surface area, and narrow pore size distribution. Mesoporous materials are a class of nanoporous materials and were discovered in the year 1992 by the Mobil oil researchers (Kresge et al. 1992; Beck et al. 1992). These materials have potential application in many fields, such as catalysis, adsorption, and biomedical engineering (Anbia and Mohammadi 2009a, b; Anbia and Parvin 2011; Anbia et al. 2014). Mesoporous carbon molecular sieves can be prepared by using silica mesoporous molecular sieves as hard templates (Ryoo et al. 1999).

In the present study, highly ordered mesoporous carbon molecular sieve designated as CMK-1 is first synthesized using mesoporous MCM-48 silica as a template and then oxidized; finally, it is modified by tetraethylenepentamine and denoted as (OCMK-1/TEPA). It has (OCMK-1/TEPA) shown high adsorption capacity for hexavalent chromium. Langmuir and Freundlich adsorption isotherms have been used to describe the equilibrium adsorption data for hexavalent chromium.

This research was done in laboratory complex of Science and Research Branch Islamic Azad University and Research Laboratory of Nanoporous Materials, Iran University of Science and Technology, during the academic year of 2013-2014.

\section{Materials and methods}

\section{Materials}

Tetraethyl orthosilicate (TEOS) as a silica source, cetyltrimethylammonium bromide (CTAB) as a surfactant, sodium hydroxide $(\mathrm{NaOH})$, sodium fluoride $(\mathrm{NaF})$ and sucrose as a carbon source, and sulfuric acid as a catalyst for synthesis of mesoporous carbon, nitric acid as an oxidizing agent, and tetraethylenepentamine and ethanol $95 \%$ for functionalization of mesoporous carbon and potassium dichromate. All these chemicals were of analytical grade and were from E. Merck (Germany).

Synthesis of mesoporous silica (MCM-48)

MCM-48 was prepared according to the procedure described by (Shao et al. 2005). In a representative synthesis, the MCM-48 was prepared as follows: $10 \mathrm{~mL}$ of tetraethyl orthosilicate was mixed with $50 \mathrm{~mL}$ of deionized water and the mixture was stirred for $45 \mathrm{~min}$ at $308 \mathrm{~K}$, then $0.9 \mathrm{~g}$ of sodium hydroxide and $0.19 \mathrm{~g}$ sodium fluoride were added to the mixture. After another $60 \mathrm{~min}, 10.61 \mathrm{~g}$ of cetyltrimethylammonium bromide was added to the mixture and further stirring continued for another $60 \mathrm{~min}$. The mixture was heated for $24 \mathrm{~h}$ at $393 \mathrm{~K}$ in an autoclave under static conditions, and the final product was filtered, washed, and dried at $373 \mathrm{~K}$. The samples were then calcined in air for $4 \mathrm{~h}$ with increasing the temperature to $823 \mathrm{~K}$ at $1{ }^{\circ} \mathrm{C} \min ^{-1}$ heating rate.

\section{Synthesis of mesoporous carbon (CMK-1)}

Mesoporous carbon (CMK-1) was prepared by using mesoporous silica material (MCM-48) as a template and sucrose as the carbon source. In a typical synthesis of mesoporous carbon, $1 \mathrm{~g}$ of template (MCM-48) was added to a solution containing $1.25 \mathrm{~g}$ of sucrose and $0.14 \mathrm{~g}$ of sulfuric acid and $5 \mathrm{~g}$ of deionized water, and the mixture was kept in an oven for $6 \mathrm{~h}$ at $373 \mathrm{~K}$. Subsequently, the oven temperature was raised to $433 \mathrm{~K}$ for another $6 \mathrm{~h}$. In order to obtain fully carbonized and polymerized sucrose inside the pores of the template, $0.8 \mathrm{~g}$ of sucrose, $0.09 \mathrm{~g}$ of sulfuric acid, and $5 \mathrm{~g}$ of deionized water were again added to the sample, and the mixture was again subjected to the thermal treatment as explained above. The templatepolymer composites were then pyrolyzed under nitrogen flow at $1173 \mathrm{~K}$ and kept under these conditions for $6 \mathrm{~h}$ to carbonize the polymer. To completely dissolve the silica template, the carbon-silica composite was washed with a $1 \mathrm{M}$ sodium hydroxide solution of $50 \% \mathrm{H}_{2} \mathrm{O}-50 \%$ ethanol at $363 \mathrm{~K}$ and then the carbon materials obtained after the silica removal were filtered, washed with ethanol, and dried at $393 \mathrm{~K}$.

\section{Chemical oxidation of mesoporous carbon (OCMK-1)}

To introduce oxygen-containing functional groups on the carbon surface, mesoporous carbon was oxidized by nitric acid under optimal condition, such as nitric acid concentration and oxidation temperature (Bazuła et al. 2008). $0.1 \mathrm{~g}$ of dried mesoporous carbon powder was treated with $15 \mathrm{~mL}$ of nitric acid solution $(2 \mathrm{M})$ for $1 \mathrm{~h}$ at $80^{\circ} \mathrm{C}$ under refluxing. Then, oxidized samples were recovered and washed with deionized water until the $\mathrm{pH}$ was close to 7 .

Functionalization of OCMK-1

with tetraethylenepentamine (OCMK-1/TEPA)

$1 \mathrm{~g}$ of tetraethylenepentamine (TEPA) was dissolved in $50 \mathrm{~g}$ ethanol under stirring for $40 \mathrm{~min}$ at room temperature, and then $2 \mathrm{~g}$ OCMK-1 was added. After refluxing for $4 \mathrm{~h}$, 
the resulting mixture was evaporated at $80{ }^{\circ} \mathrm{C}$. Finally, the samples were dried in air for $1 \mathrm{~h}$ at $100^{\circ} \mathrm{C}$ and denoted as OCMK-1/TEPA.

\section{Characterization}

The X-ray powder diffraction (XRD) patterns were recorded on a Philips 1830 diffractometer using $\mathrm{Cu}-\mathrm{K} \alpha$ radiation. The diffractograms were recorded in the $2 \theta$ range of $1-10$ with a $2 \theta$ step size of $0.018^{\circ}$ with a step time of $1 \mathrm{~s}$. Adsorption-desorption isotherms of the synthesized materials were analyzed at $77 \mathrm{~K}$ on Micromeritics model ASAP 2010 sorptometer to determine pore size distribution and surface area. The surface area of the sample was measured by Brunaure-Emmett-Teller (BET) method while pore size distributions were calculated by the Barrett-JoynerHalenda (BJH) method. Scanning electron microscopy images were obtained with JEOL 6300F Scanning electron microscopy and the Fourier transform infrared spectra for the unmodified and modified samples were measured on a DIGILABFTS 7000 instrument under attenuated total reflection (ATR) mode using a diamond module.

\section{Batch adsorption experiments}

To study the effect of important parameters such as the $\mathrm{pH}$, contact time, initial $\mathrm{Cr}(\mathrm{VI})$ concentration, and adsorbent dose on the removal of $\mathrm{Cr}(\mathrm{VI})$, batch experiments were conducted. In each batch, the mixture of $25 \mathrm{~mL}$ $\mathrm{Cr}(\mathrm{VI})$ solution of known $\mathrm{pH}$, concentration, and a known amount of adsorbent was taken in 50-mL stoppered conical flask. The resulting mixture was continuously shaken in a shaking bath with a speed of 160 shakes $\min ^{-1}$ at $293 \mathrm{~K}$ for $1 \mathrm{~h}$ until equilibrium was reached. Chromium stock solution was prepared by dissolving potassium dichromate $\left(\mathrm{K}_{2} \mathrm{Cr}_{2} \mathrm{O}_{7}\right)$ in distilled water. The concentration of aqueous $\mathrm{Cr}(\mathrm{VI})$ solution in the supernatant was determined by a UV spectrophotometer (UV mini 1240 Shimadzu) at the wavelength of $257 \mathrm{~nm}$. The effect of solution $\mathrm{pH}$ on $\mathrm{Cr}(\mathrm{VI})$ removal was investigated over a $\mathrm{pH}$ range of 1-9. The $\mathrm{pH}$ was adjusted using $0.10 \mathrm{M} \mathrm{HCl}$ or $0.10 \mathrm{M} \mathrm{NaOH}$ aqueous solution. The experiments were also done by varying the amount of adsorbents (0.002$0.02 \mathrm{~g} / 25 \mathrm{~mL})$ and the concentration of $\mathrm{Cr}(\mathrm{VI})$ solution $\left(100-1,000 \mathrm{mg} \mathrm{L}^{-1}\right)$. For adsorption isotherm, $\mathrm{Cr}(\mathrm{VI})$ solutions of different concentrations $\left(100-1,000 \mathrm{mg} \mathrm{L}^{-1}\right)$ were shaken with known amount of adsorbent $(0.01 \mathrm{~g})$ till the equilibrium was achieved. After that the residual $\mathrm{Cr}(\mathrm{VI})$ concentration of the solution was determined. The amount of adsorbed $\mathrm{Cr}(\mathrm{VI})$ per gram of OCMK-1/TEPA at equilibrium, $q_{\mathrm{e}}\left(\mathrm{mg} \mathrm{g}^{-1}\right)$, was obtained by the following equation:
$q_{\mathrm{e}}=\frac{\left(C_{0}-C_{\mathrm{e}}\right) V}{W}$

where $C_{0}$ and $C_{\mathrm{e}}\left(\mathrm{mg} \mathrm{L}^{-1}\right)$ are the initial and equilibrium concentrations of $\mathrm{Cr}(\mathrm{VI})$, respectively. $V(\mathrm{~L})$ is the volume of the solution, and $W(\mathrm{~g})$ is the weight of adsorbent used.

\section{Adsorption kinetics of $\mathrm{Cr}(\mathrm{VI})$}

For the adsorption kinetics measurement of $\mathrm{Cr}(\mathrm{VI})$ on the adsorbent, $25 \mathrm{~mL}$ of $\mathrm{Cr}(\mathrm{VI})$ solution with an initial concentration of $500 \mathrm{mg} \mathrm{L}^{-1}$ was introduced into the flask and mixed with $0.01 \mathrm{~g}$ of OCMK-1/TEPA. The solution was stirred continuously at 298 K. Samples were taken from the solution by filtration at different time intervals. The concentration of $\mathrm{Cr}(\mathrm{VI})$ in the remaining solution was determined, and the amount of adsorption $\left(q_{t}\right)$ was calculated according to Eq. (2).

$q_{t}=\frac{\left(C_{0}-C_{t}\right) V}{W}$

where $q_{t}$ is the amount of adsorption at time $t\left(\mathrm{mg} \mathrm{g}^{-1}\right), C_{0}$ is the initial concentration of $\mathrm{Cr}(\mathrm{VI})$ in the solution ( $\left.\mathrm{mg} \mathrm{L}^{-1}\right), C_{t}$ is the concentration of $\mathrm{Cr}(\mathrm{VI})$ in the solution at time $t\left(\mathrm{mg} \mathrm{L}^{-1}\right), V$ is the volume of the solution (L), and $W$ is the mass of OCMK-1/TEPA $(\mathrm{g})$.

\section{Results and discussion}

Physical and chemical properties of the adsorbents

The mesoporous carbon and modified mesoporous carbon prepared in this study were examined by nitrogen adsorption-desorption analysis, X-ray diffraction (XRD) techniques, and scanning electron microscopy. Figure 1 shows the nitrogen adsorption and desorption isotherms measured at $77 \mathrm{~K}$. BET surface areas and the pore size determined by the BJH method for the synthesized mesoporous sorbents were determined by the adsorption branches of the isotherms. The two mesoporous materials yield a type IV isotherm. It can be seen that after modifying the obtained carbons still have type IV isotherms, indicating that mesoporosity is still preserved.

The narrow pore size distributions centered at about $3.2 \mathrm{~nm}$ for CMK-1 and $2.5 \mathrm{~nm}$ for OCMK-1/TEPA clearly show that during the preparation of OCMK-1/TEPA the removal of silica did not alter the mesopore structure of CMK-1. Table 1 summarizes the important physical properties of mesoporous sorbents.

XRD data of OCMK-1/TEPA and CMK-1 were obtained using $\mathrm{Cu}-\mathrm{K} \alpha$ radiation of wavelength $0.154 \mathrm{~nm}$. The XRD patterns of the mesoporous carbon CMK-1 and 

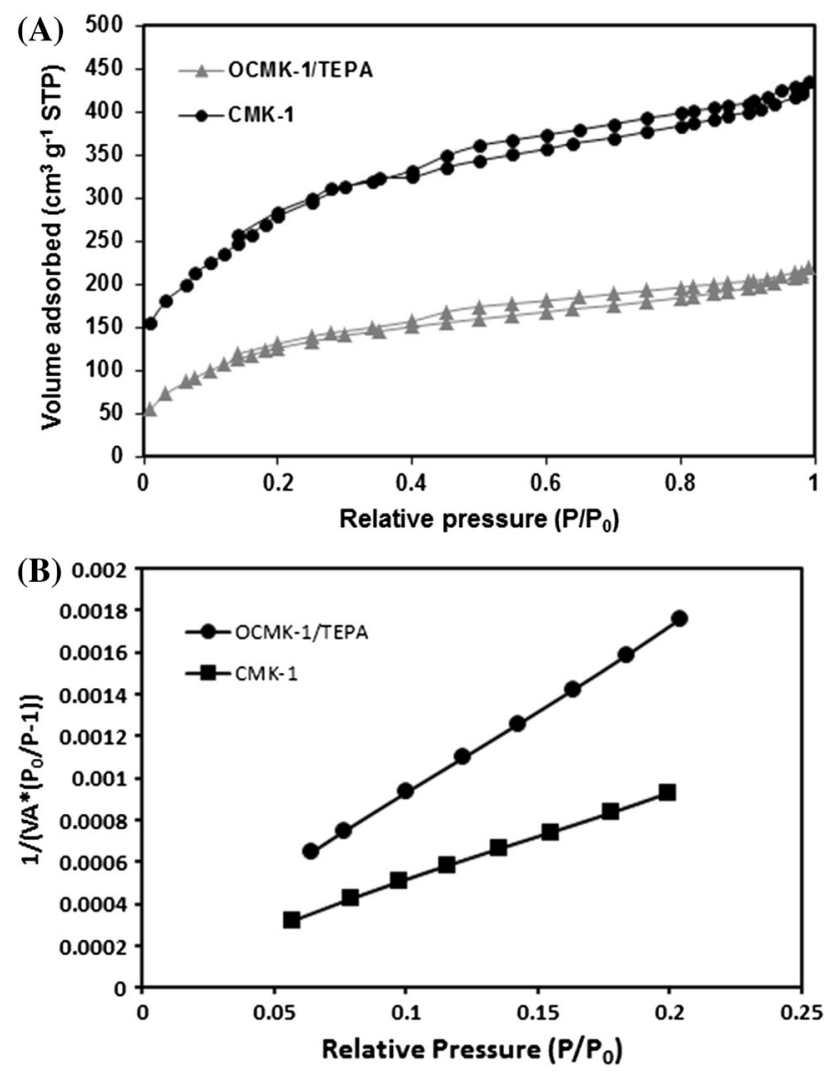

Fig. 1 a Adsorption-desorption isotherms at $77 \mathrm{~K}$ on CMK-1 and OCMK-1/TEPA. b BET surface area plot of CMK-1 (BET surface area: 1,010.1617, slope: 0.004222, Y-Intercept: 0.000088) and OCMK-1/TEPA (BET surface area: 542.0922, slope: 0.007894, Y-Intercept: 0.000007)

Table 1 Textural properties determined from nitrogen adsorptiondesorption experiments at $77 \mathrm{~K}$

\begin{tabular}{llcl}
\hline Adsorbent & $d$ spacing $(\mathrm{nm})$ & $A_{\mathrm{BET}}\left(\mathrm{m}^{2} \mathrm{~g}^{-1}\right)$ & $V_{\mathrm{p}}\left(\mathrm{cm}^{3} \mathrm{~g}^{-1}\right)$ \\
\hline CMK-1 & 3.2 & $1,010.16$ & 0.62 \\
OCMK-1/TEPA & 2.5 & 542.09 & 0.34 \\
\hline
\end{tabular}

$d$ spacing pore size of particle, $A_{\mathrm{BET}}$ the surface area of synthesis material, $V_{\mathrm{p}}$ volume of pore

the functionalized sample OCMK-1/TEPA are shown in Fig. 2a. The XRD pattern for CMK-1 exhibits an intense diffraction peak and two weak peaks indexed as $\left(\begin{array}{lll}1 & 1 & 0\end{array}\right),\left(\begin{array}{ll}2 & 1\end{array}\right.$

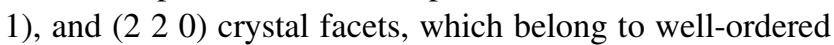
cubic pores (Jun et al. 2000). The (1 10$)$, (2 11 1), and (2 20 ) peaks for the CMK-1 carbon were retained after the modification by TEPA but the intensities were slightly reduced that might be due to the partial damage of the mesoporous (cubic) structure or due to the decreased contrast between walls and pores because of the cleavage of the carbon species from the pore walls. But the XRD patterns indicate that two samples have highly ordered uniform mesopores.
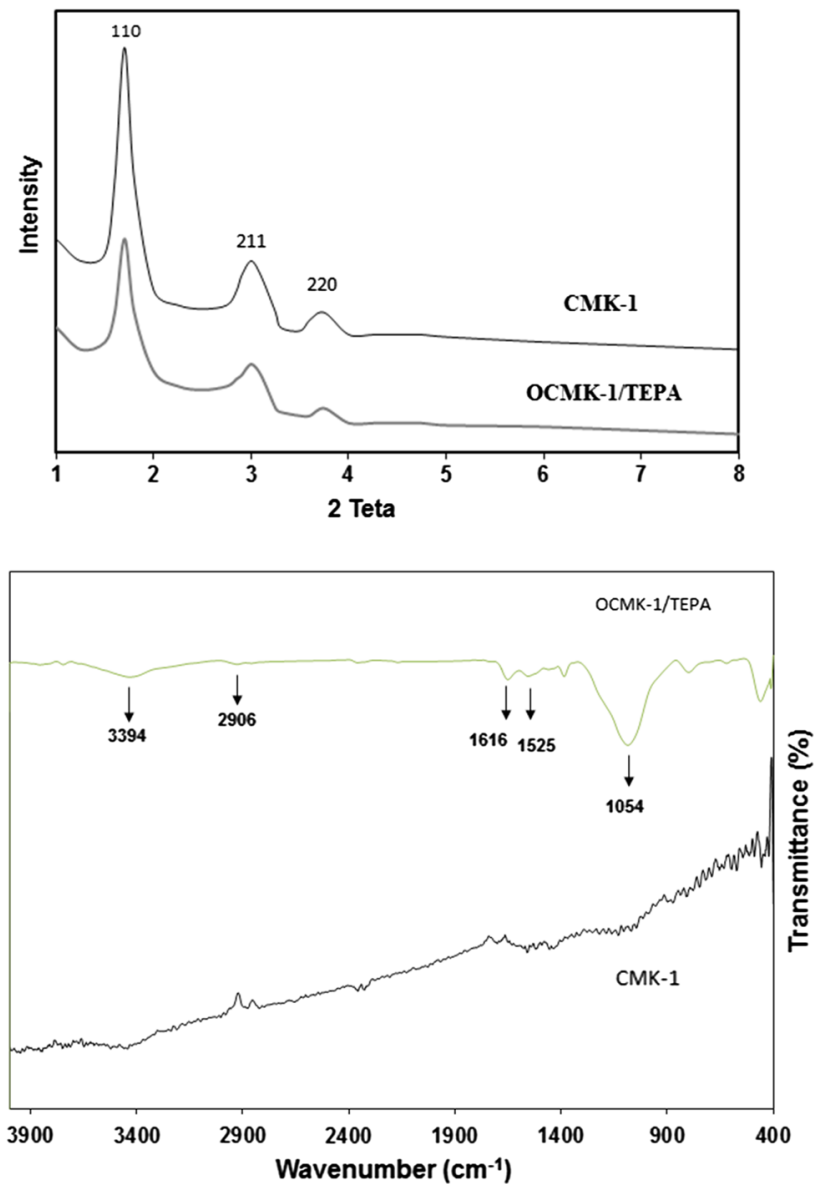

Fig. 2 a XRD patterns of CMK-1 and OCMK-1/TEPA b FTIR spectra of CMK-1 and composite OCMK-1/TEPA

The FT-IR technique was used to monitor changes on the surface of the ordered mesoporous carbon and the content of the introduced TEPA containing functional surface group. Figure $2 \mathrm{~b}$ shows the FT-IR spectra of unfunctionalized and amino-functionalized CMK-1 materials over the range of $4,000-400 \mathrm{~cm}^{-1}$. In general, the functionalized mesoporous carbon with amino group shows a broad $\mathrm{NH}_{2}$ stretching at $3,250-3,550 \mathrm{~cm}^{-1}$, an $\mathrm{N}-\mathrm{H}$ peak at $1,640-1,560 \mathrm{~cm}^{-1}$. The symmetric and asymmetric stretching vibrations of the $-\mathrm{NH}_{2}$ groups appear at $3,250-3,450 \mathrm{~cm}^{-1}$.

In Fig. 3, SEM image of OCMK-1/TEPA is compared with CMK-1. The SEM micrographs demonstrate that the TEPA functionalization did not make any noticeable damage to the surface morphology of OCMK-1/TEPA since both the SEM images of CMK-1 before and after surface modified show the rod-like morphology.

The scanning electron microscopy showed that the porous carbon particles retained the crystal morphologies for the silica template. 
Fig. 3 SEM images of CMK-1 (a) and OCMK-1/TEPA (b)

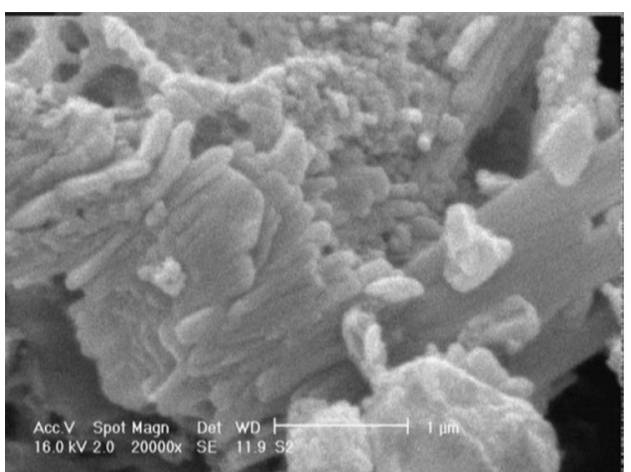

(A)

$[16 \mathrm{KV}, 20000 \mathrm{x}]$

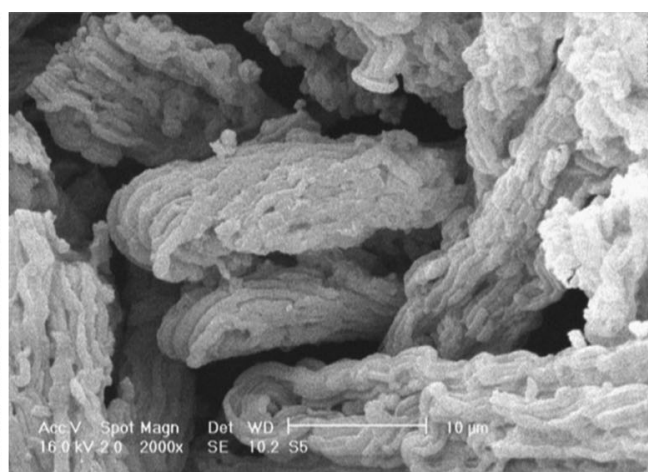

(B)

[16KV, 2000x]

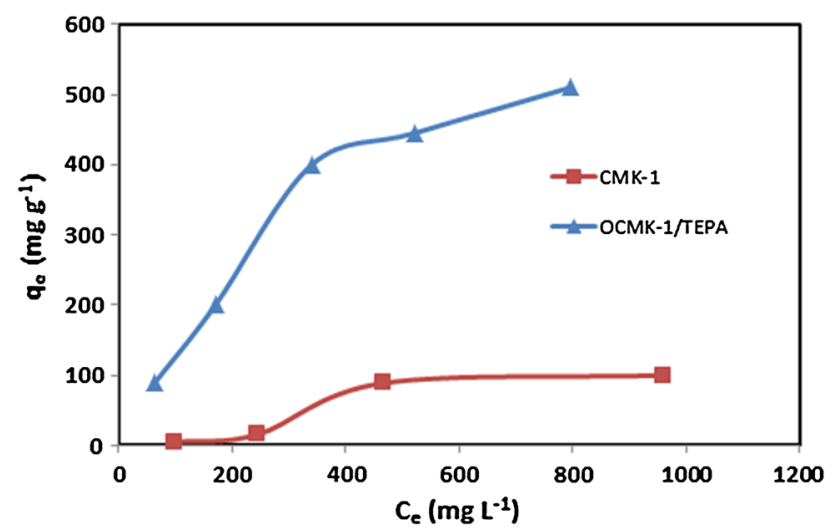

Fig. 4 Adsorption isotherm for $\mathrm{Cr}(\mathrm{VI})$ on CMK-1and OCMK-1/ TEPA (contact time $=1 \mathrm{~h}$, adsorbent dosage $=0.4 \mathrm{~g} \mathrm{~L}^{-1}, \mathrm{pH} 3$ )

\section{Adsorption studies}

\section{The effect of chemical modification}

In order to evaluate the efficiency of the prepared adsorbents, the equilibrium adsorption of the hexavalent chromium is studied as a function of equilibrium concentration. The adsorption isotherms of $\mathrm{Cr}(\mathrm{VI})$ in OCMK-1/TEPA and CMK-1 are shown in Fig. 4. It is seen that the order of adsorption in terms of the amount adsorbed $\left(\mathrm{mg} \mathrm{g}^{-1}\right)$ at different conditions is OCMK-1/TEPA > CMK-1. When the initial concentration $\left(C_{0}\right)$ of $\mathrm{Cr}(\mathrm{VI})$ increases from 100 to $1,000 \mathrm{mg} \mathrm{L}^{-1}$, the adsorption capacity $\left(q_{\mathrm{e}}\right)$ increases from 90 to $510 \mathrm{mg} \mathrm{g}^{-1}$. However, this may be because of the increase in the number of $\mathrm{Cr}(\mathrm{VI})$ ions competing for the available sites on the surface of the adsorbent. The results provided in Fig. 5 show that CMK-1 modified with tetraethylenepentamine has a very high adsorption capacity for chromium(VI).

The high adsorption capacity of modified mesoporous carbon can be explained by several facts. This may be because of the hydrophobicity created by amine group. It is also surmised that the presence of a free electron pair causes more interaction between dichromate anion and the adsorbent (OCMK-1/TEPA). In other words, dichromate anions are weak acids and there are acid and alkaline interactions between amine groups and dichromate anion. Schematic illustration of preparation of OCMK-1/TEPA and their $\mathrm{Cr}(\mathrm{VI})$ adsorption-reduction mechanism is shown in Fig. 5.

\section{The effect of contact time and concentration on the adsorption}

The adsorbate concentration and contact time between adsorbent and adsorbate species play a significant role in the removal of pollutants from water and wastewater by adsorption at a particular temperature and $\mathrm{pH}$. The effect of contact time for the removal of hexavalent chromium by adsorbent is shown in Fig. 6. The $\mathrm{Cr}(\mathrm{VI})$ is rapidly adsorbed in the first 20-25 min, and then the adsorption rate decreases gradually and reaches to equilibrium in about $1 \mathrm{~h}$. This is clear that during the initial stage a large number of unoccupied surface sites are available for the adsorption, and after a passing of time, the remaining vacant surface places are difficult to be occupied because of repulsion between the solute molecules of the solid and bulk phases.

The effect of concentration on the equilibration time was studied as a function of initial concentration of $\mathrm{Cr}(\mathrm{VI})$. As can be seen from Fig. 6, the amount of $\mathrm{Cr}(\mathrm{VI})$ eliminated by the adsorbent increases with increase in $\mathrm{Cr}(\mathrm{VI})$ concentration and it was found that the time required to achieve a definite equilibrium adsorption is independent of the initial concentration.

\section{Effect of $p H$ on the chromium(VI) adsorption}

The $\mathrm{pH}$ of the aqueous solution is a significant parameter for the removal of metal ions by adsorption (Donmez and Aksu 2002). In the present work, adsorption of hexavalent 
Fig. 5 Schematic illustration of preparation of OCMK-1/TEPA and their $\mathrm{Cr}(\mathrm{VI})$ adsorptionreduction mechanism

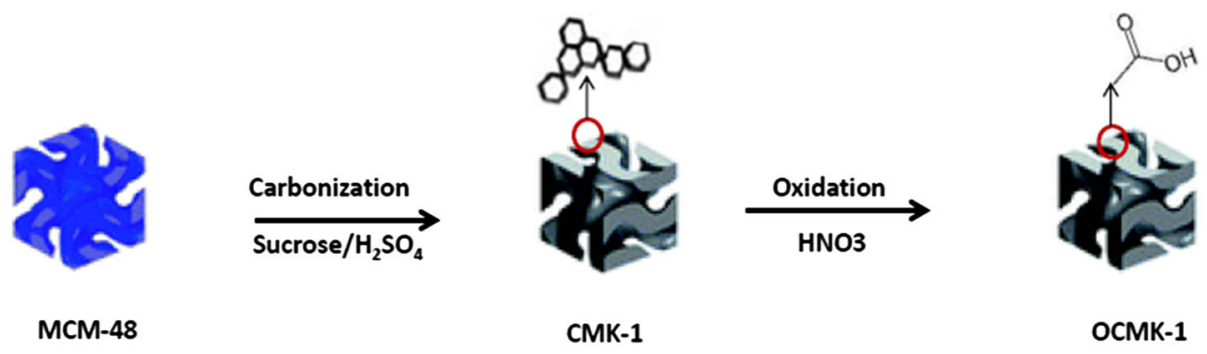

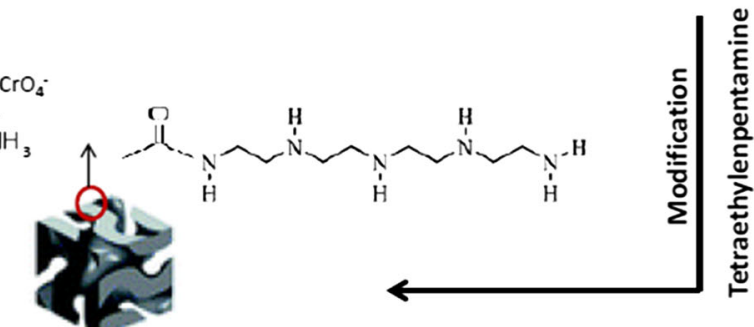

OCMK-1/TEPA

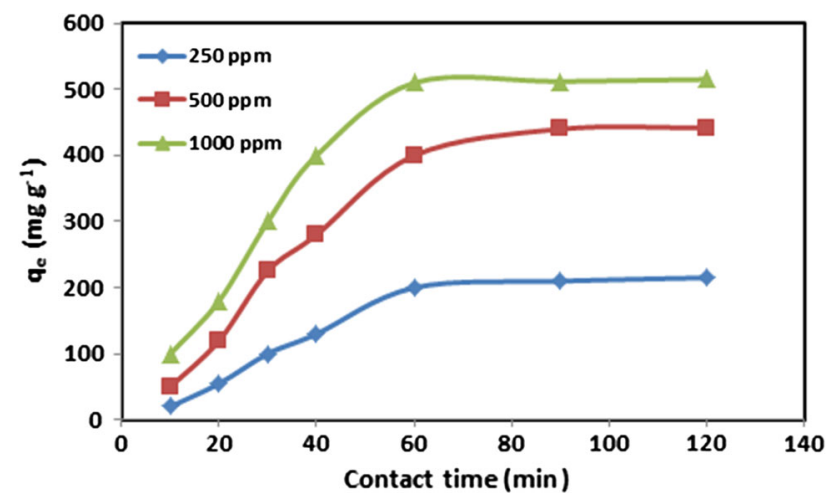

Fig. 6 Effect of initial concentration and contact time for removal of $\mathrm{Cr}(\mathrm{VI})$ on OCMK-1/TEPA (adsorbent dosage $=0.4 \mathrm{~g} \mathrm{~L}^{-1}, \mathrm{pH} 3$ )

chromium is studied at the initial $\mathrm{pH}$ range of $1-9$. The effect of initial $\mathrm{pH}$ on the adsorption of hexavalent chromium is shown in Fig. 7a. At this $\mathrm{pH}$ range, the maximum adsorption on composite in $500 \mathrm{ppm}$ was $400 \mathrm{mg} \mathrm{g}^{-1}$ at pH 3.

High adsorption, as well as uptake, at lower $\mathrm{pH}$ values can be well explained by protonation properties of the adsorbent. In the studied $\mathrm{pH}$ range, the dominant species of $\mathrm{Cr}(\mathrm{VI})$ in the solution are $\mathrm{HCrO}_{4}^{-}$anion, which can be easily adsorbed by protonated active sites of the OCMK-1/ TEPA. The high $\mathrm{Cr}(\mathrm{VI})$ adsorption capacity at low $\mathrm{pH}$ could be because of the electrostatic attraction between $\mathrm{HCrO}_{4}{ }^{-}$ions and positively charged groups of OCMK-1/ TEPA surfaces. In addition, as the $\mathrm{pH}$ increases, more $\mathrm{OH}^{-}$ ions compete with $\mathrm{Cr}(\mathrm{VI})$ ions for positively charged amino groups. Similarly, at equilibrium $\mathrm{pH}$ below two, the adsorption capacity decreases with lower $\mathrm{pH}$, due to the increase in $\mathrm{H}_{2} \mathrm{CrO}_{4}$ which has no attraction to positively charged amino groups.
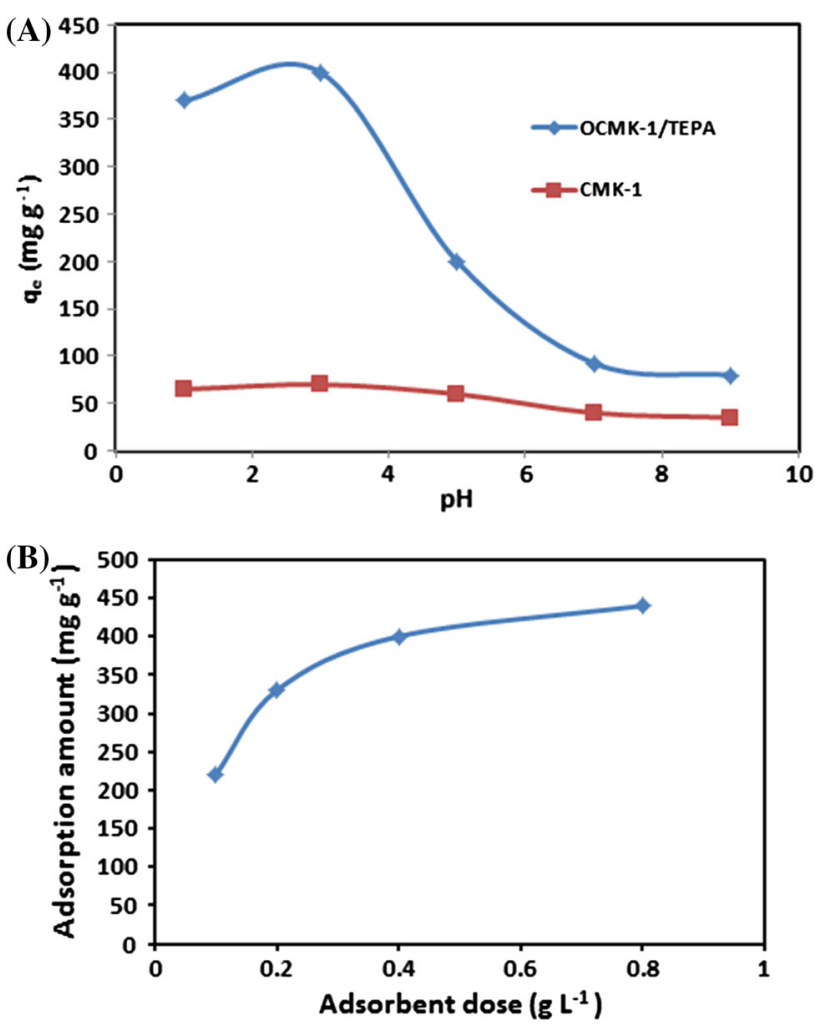

Fig. 7 a Effect of $\mathrm{pH}$ on removal of $\mathrm{Cr}(\mathrm{VI})$ with OCMK-1/TEPA (initial concentration $=500 \mathrm{mg} \mathrm{L}^{-1}$, adsorbent dose $0.4 \mathrm{~g} \mathrm{~L}^{-1}$, contact time $=1 \mathrm{~h})$. b Effect of adsorbent dose on removal of $\mathrm{Cr}(\mathrm{VI})$ with OCMK-1/TEPA (initial concentration $=500 \mathrm{mg} \mathrm{L}^{-1}$, contact time $=1 \mathrm{~h}, \mathrm{pH} 3$ )

\section{The effect of adsorbent dose}

The effect of adsorbent dose on adsorption amount $q_{\mathrm{e}}$ $\left(\mathrm{mg} \mathrm{g}^{-1}\right)$ of $\mathrm{Cr}(\mathrm{VI})$ is depicted in Fig. 7b. It is increased 
with the increase in adsorbent dose. This increase in loading capacity is due to the availability of a greater number of active sites of the adsorbent. The present study shows that the OCMK-1/TEPA is an effective adsorbent for the removal of $\mathrm{Cr}(\mathrm{VI})$ from aqueous solution.

The analysis of adsorption isotherms

The adsorption equilibrium information is the most important part in understanding an adsorption process. In the case of the models with two parameters, the Langmuir and Freundlich equations are largely used. The Langmuir isotherm model supposes that adsorption takes place at the specific homogeneous sites within the adsorbent (Langmuir 1916). Also, all sorption sites are identical and energetically equivalent. This isotherm is often described in the form of the following Eq. (3):

$\frac{C_{\mathrm{e}}}{q_{\mathrm{e}}}=\frac{1}{q_{\mathrm{m}} b}+\frac{1}{q_{\mathrm{m}}} C_{\mathrm{e}}$

where $q_{\mathrm{e}}$ is the adsorbed amount of $\mathrm{Cr}(\mathrm{VI})$ under equilibrium $\left(\mathrm{mg} \mathrm{g}^{-1}\right), C_{\mathrm{e}}$ is the equilibrium concentration of $\mathrm{Cr}(\mathrm{VI})$ in solution $\left(\mathrm{mg} \mathrm{L}^{-1}\right), q_{\mathrm{m}}$ is the monolayer adsorption capacity $\left(\mathrm{mg} \mathrm{g}^{-1}\right)$, and $b\left(\mathrm{~L} \mathrm{mg}^{-1}\right)$ is the constant related to the free energy of adsorption.

The empirical Freundlich equation is based on sorption on heterogeneous surface and is given by (Freundlich 1906):

$\ln q_{\mathrm{e}}=\ln K_{\mathrm{F}}+\left(\frac{1}{n}\right) \ln C_{\mathrm{e}}$

where $K_{\mathrm{F}}$ is the Freundlich isotherm constant concerned with the relative adsorption capacity, and $\mathrm{n}$ is a constant related to the intensity of adsorption. By plotting $\ln q_{\mathrm{e}}$ versus $\ln C_{\mathrm{e}}$, the value of $K_{\mathrm{F}}$ was obtained from the intercept and $\mathrm{n}$ from the slope. The slope and the intercept correspond to $(1 / n)$ and $K_{\mathrm{F}}$, respectively.

The Freundlich adsorption isotherm is an indication of surface heterogeneity of the adsorbent while Langmuir isotherm assumes that adsorption takes place at the surface homogeneous sites. The fitting results, i.e., isotherm parameters and the coefficients of determination, $R^{2}$, are shown in Table 2.

It is clear that Freundlich isotherm fits the data better than Langmuir isotherm. The modified mesoporous carbon adsorbent used in this work has a relatively large adsorption
Table 2 Langmuir and Freundlich constants for adsorption of $\mathrm{Cr}(\mathrm{VI})$ on OCMK-1/TEPA

\begin{tabular}{lllllll}
\hline \multicolumn{2}{l}{ Langmuir constants } & & & \multicolumn{4}{l}{ Freundlich constants } \\
\cline { 1 - 2 } $\begin{array}{l}q_{\mathrm{m}} \\
\left.\mathrm{mg} \mathrm{g}^{-1}\right)\end{array}$ & $b\left(\mathrm{~L} \mathrm{mg}^{-1}\right)$ & $R^{2}$ & & $\begin{array}{l}K_{\mathrm{F}} \\
\left(\mathrm{mg} \mathrm{g}^{-1}\right)\end{array}$ & $n\left(\mathrm{~L} \mathrm{mg}^{-1}\right)$ & $R^{2}$ \\
\hline 833.3 & 0.0019 & 0.983 & 4.378 & 1.3544 & 0.9946 \\
\hline
\end{tabular}

capacity. This indicates that OCMK-1/TEPA is very effective to remove $\mathrm{Cr}(\mathrm{VI})$ from aqueous solution.

Kinetic modelling

In the present study, the sorption data were analyzed using two simple kinetic models, first- and second-order models that are explained as follows.

\section{Pseudo-first-order and second-order}

The pseudo-first-order equation is expressed (Robinson et al. 2002; Malik 2003) as:

$\ln \left(q_{\mathrm{e}}-q_{t}\right)=\ln q_{\mathrm{e}}-k_{1} t$

where $q_{\mathrm{e}}$ and $q_{t}$ are amounts of $\mathrm{Cr}(\mathrm{VI})$ adsorbed $\left(\mathrm{mg} \mathrm{g}^{-1}\right)$ at equilibrium and time $t(\mathrm{~min})$, respectively, and $k_{1}$ is the rate constant of pseudo-first-order adsorption $\left(\mathrm{min}^{-1}\right)$. The $k_{1}$ values and $q_{\mathrm{e}}$ were calculated from the slope and intercept from the plots of $\log \left(q_{\mathrm{e}}-q_{t}\right)$ versus $t$ for different concentration. These values and the correlation coefficient are given in Table 3. Also, the calculated $q_{\mathrm{e}}$ values agree with the experimental data $\left(q_{\mathrm{e}, \exp }\right)$. This indicates that the adsorption perfectly complies with the pseudo-first-order reaction.

The pseudo-second-order kinetic model (Ho and McKay 1999) is as follows:

$\frac{t}{q_{t}}=\frac{1}{k_{2} q_{\mathrm{e}}^{2}}+\left(\frac{1}{q_{\mathrm{e}}}\right) t$

where $k_{2}$ is the rate constant of pseudo-second-order adsorption $\left[\mathrm{g}(\mathrm{mg} \mathrm{min})^{-1}\right]$. The $q_{\mathrm{e}}$ and $k_{2}$ values were calculated from slope and intercept of plots of $\left(t / q_{t}\right)$ versus $t$ for the pseudo-second-order model, respectively. The $q_{\mathrm{e} \text { exp }}$ values do not agree with calculated ones, obtained from the plots. These results show that the adsorption of $\mathrm{Cr}(\mathrm{VI})$ onto

Table 3 Pseudo-first-order and pseudo-second-order constants for the removal Cr(VI) by OCMK-1/TEPA

\begin{tabular}{|c|c|c|c|c|c|c|c|}
\hline \multirow[t]{2}{*}{$\mathrm{C}_{0}\left(\mathrm{mg} \mathrm{L}^{-1}\right)$} & \multirow[t]{2}{*}{$q_{\mathrm{e}, \exp }\left(\mathrm{mg} \mathrm{g}^{-1}\right)$} & \multicolumn{3}{|c|}{ Pseudo-first-order constants } & \multicolumn{3}{|c|}{ Pseudo-second-order constants } \\
\hline & & $q_{\mathrm{e}, \mathrm{cal}}\left(\mathrm{mg} \mathrm{g}^{-1}\right)$ & $k_{1}\left[\mathrm{~g}(\mathrm{mg} \min )^{-1}\right]$ & $R^{2}$ & $q_{\mathrm{e}, \mathrm{cal}}\left(\mathrm{mg} \mathrm{g}^{-1}\right)$ & $k_{2}\left[\mathrm{~g}(\mathrm{mg} \min )^{-1}\right]$ & $R^{2}$ \\
\hline 250 & 200.3 & 267.73 & 0.035 & 0.9943 & 603.11 & $1.428 \times 10^{-5}$ & 0.7676 \\
\hline 500 & 400 & 606.679 & 0.0436 & 0.9923 & 694.22 & $2.408 \times 10^{-5}$ & 0.6097 \\
\hline
\end{tabular}




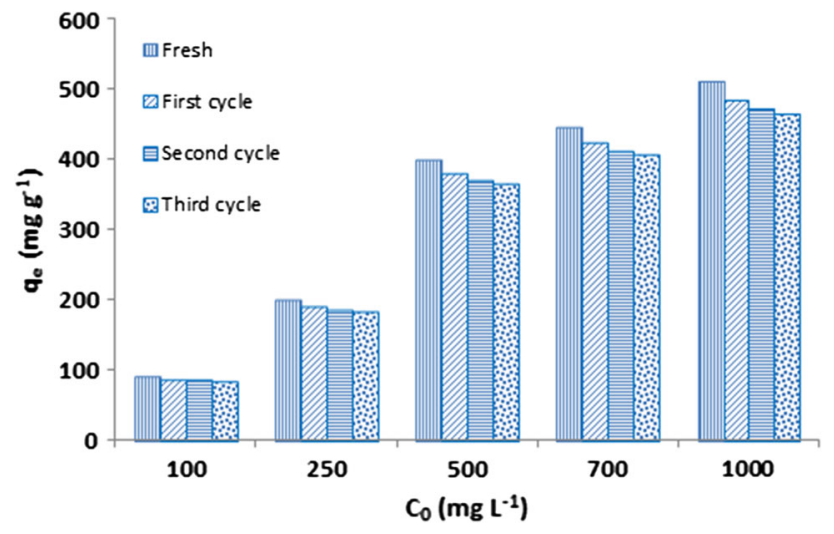

Fig. 8 Regenerated use of OCMK-1/TEPA adsorbent for removal of $\mathrm{Cr}(\mathrm{VI})(\mathrm{pH} 3$, agitation time $=1 \mathrm{~h}$, concentration of $\mathrm{HCl}=0.20 \mathrm{M})$

mesoporous carbon modified with TEPA is not a pseudosecond-order reaction.

Table 3 shows that the correlation coefficients of firstorder kinetics model are greater than second-order kinetics.

Desorption and reusability studies

Regeneration studies help the recycling of adsorbent and the recovery of the metal ions from wastewater (Saeed and Iqbal 2003). The regeneration of the adsorbent is one of the important factors which affect the overall cost of the adsorption process. Regeneration of $\mathrm{Cr}(\mathrm{VI})$ using an $\mathrm{HCl}$ solution by disruption of coordination of $\mathrm{Cr}(\mathrm{VI})$ with the surface of OCMK-1/TEPA and subsequent release into desorption medium was studied (Fig. 8). The results show that with increasing in concentration of $\mathrm{HCl}$ solution the desorption also increases, but becomes constant at $0.2 \mathrm{M}$ $\mathrm{HCl}$ for $\mathrm{Cr}(\mathrm{VI})$. The adsorption-desorption studies of the OCMK-1/TEPA indicated a loss in the adsorption capacity of $5 \%$ after the first cycle, $7.5 \%$ after second cycle, and $9 \%$ after the third cycle compared to the initial cycle, indicating a good regeneration capacity of the adsorbent. These results indicate that after four consecutive cycles of adsorption-desorption, the adsorption capacity of $\mathrm{Cr}(\mathrm{VI})$ has decreased slightly. The main reason for this can be attributed to the ordered structure of the porous adsorbents.

\section{Comparison with other adsorbents}

The value of $q_{\max }$ is important to identify the sorbent which shows the highest adsorption capacity and is useful in scale-up process. Comparison of $\mathrm{Cr}(\mathrm{VI})$ adsorption capacities on different adsorbents is shown in Table 4. By comparing the synthesized OCMK-1/TEPA with other adsorbents, it can be seen that OCMK-1/TEPA has high adsorption capacity for $\mathrm{Cr}(\mathrm{VI})$ and also has very low equilibrium time $(1 \mathrm{~h})$.

Table 4 Comparison of adsorption capacity of hexavalent chromium onto various adsorbents

\begin{tabular}{|c|c|c|c|c|c|}
\hline Adsorbent & Temperature $\left({ }^{\circ} \mathrm{C}\right)$ & $\mathrm{pH}$ & $\begin{array}{l}\text { Equilibrium } \\
\text { time (min) }\end{array}$ & $q_{\mathrm{m}}\left(\mathrm{mg} \mathrm{g}^{-1}\right)$ & References \\
\hline $\mathrm{N}$-doped porous carbon with magnetic particles & 25 & 3 & 30 & 16 & Li et al. (2013) \\
\hline Limonite & 25 & 5.5 & 120 & 10.03 & Baig et al. (2013) \\
\hline Activated carbons & 60 & 2 & 1,440 & 262 & Ozdemir et al. (2011) \\
\hline $\begin{array}{l}\text { Amphiphilic gels based on 2-(dimethylamino)ethyl } \\
\text { methacrylate modified with 1-bromoalkanes }\end{array}$ & 25 & 4.5 & 3,000 & 210 & Cheng et al. (2011) \\
\hline Bio-charcoal from sewage sludge & 25 & 1 & 600 & 61.3 & Xi and Guo (2013) \\
\hline Activated carbon-based iron & 22 & 4 & 2,880 & 68.49 & Liu et al. (2012) \\
\hline $\begin{array}{l}\text { Nanocarbonate hydroxylapatite of different } \\
\mathrm{Ca} / \mathrm{P} \text { molar ratios }\end{array}$ & 25 & 3 & 60 & 90.91 & Tang et al. (2013) \\
\hline Natural Akadama clay & - & 2 & 180 & 4.29 & Zhao et al. (2013) \\
\hline Amino-functionalized carbon spheres & - & 2 & 1,440 & 240 & Wang et al. (2012) \\
\hline Polyaniline/humic acid composite & 25 & 5 & 1,440 & 29.26 & Li et al. (2011) \\
\hline Polyphenylene sulfide based anion exchange fiber & 20 & 3.5 & 20 & 166.39 & Huang et al. (2012) \\
\hline Zeolite prepared from raw fly ash & 40 & 2 & 240 & 41.32 & HosseiniAsl et al. (2013) \\
\hline $\begin{array}{l}\text { Nanoporous carbon modified with } \\
\text { tetraethylenepentamine (OCMK-1/TEPA) }\end{array}$ & 25 & 3 & 60 & 510 & Present study \\
\hline
\end{tabular}




\section{Conclusion}

In this study, tetraethylenepentamine (TEPA) grafted onto oxidized mesoporous carbon has been successfully synthesized and applied in the adsorption of hexavalent chromium. The mesoporous carbon grafted with TEPA easily adsorbs $\mathrm{Cr}(\mathrm{VI})$ at $\mathrm{pH}$ above three and exhibits adsorption capacity up to $510 \mathrm{mg} \mathrm{g}^{-1}$. This work illustrates that it is possible to achieve high adsorption capacity for the removal of chromium(VI) from aqueous solutions using mesoporous carbon modified with tetraethylenepentamine (OCMK-1/TEPA). This may be because of the hydrophobicity created by amine group. It is also surmised that the presence of a free electron pair causes more interaction between dichromate anion and adsorbent (OCMK-1/TEPA). In other words, dichromate anions are weak acids, and there are acid and alkaline interactions among amine groups and dichromate anion. The adsorption process was fast enough, as maximum removal takes place within $60 \mathrm{~min}$. The equilibrium adsorption data are satisfactorily fitted to Freundlich isotherm model, and kinetics data were best fitted to the pseudo-first-order model. This developed adsorbent can be easily used in the removal of $\mathrm{Cr}(\mathrm{VI})$ from industrial wastewater systems.

Acknowledgments The authors are thankful to Research Laboratory of Nanoporous Materials (Iran University of Science and Technology), Nanotechnology Initiative Council, and Science and Research Branch of Islamic Azad University for considerable experimental help and laboratory support.

\section{References}

Ai Z, Cheng Y, Zhang L, Qiu J (2008) Efficient removal of Cr(VI) from aqueous solution with $\mathrm{Fe} @ \mathrm{Fe}_{2} \mathrm{O}_{3}$ core-shell nanowires. Environ Sci Technol 42:6955-6960

Alidokht L, Khataee AR, Reyhanitabar A, Oustan S (2011) Reductive removal of $\mathrm{Cr}(\mathrm{VI})$ by starch-stabilized $\mathrm{Fe}^{0}$ nanoparticles in aqueous solution. Desalination 270:105-110

Anbia M, Ghaffari A (2009) Adsorption of phenolic compounds from aqueous solutions using carbon nanoporous adsorbent coated with polymer. Appl Surf Sci 255:9487-9492

Anbia M, Mandegarzad S (2012) Enhanced hydrogen sorption on modified MIL-101 with Pt/CMK-3 by hydrogen spillover effect. J Alloys Compd 532(15):61-67

Anbia M, Mohammadi K (2009a) An effective method for removal of dichromate ion and furfural from aqueous solutions using a nanoporous adsorbent. Asian J Chem 21(5):3347-3354

Anbia M, Mohammadi N (2009b) A nanoporous adsorbent for the removal of furfural from aqueous solutions. Desalination 249:150-153

Anbia M, Parvin Z (2011) Desulfurization of fuels by means of a nanoporous carbon adsorbent. Chem Eng Res Des 89(6):64-647

Anbia M, Rofouei M, Husain SW (2006) Synthesis of mesoporous lanthanum phosphate and its use as a novel sorbent. Chin J Chem 24:1026-1030
Anbia M, Neyzehdar M, Ghaffarinejad A (2014) Humidity sensitive behavior of $\mathrm{Fe}\left(\mathrm{NO}_{3}\right)_{3}$-loaded mesoporous silica MCM-41. Sens Actuators B Chem 193:225-229

Baig SA, Wang Q, Lv X, Xu X (2013) Removal of hexavalent chromium by limonite in aqueous solutions. Hydrometallurgy 138:33-39

Bazuła PA, Lu AH, Nitz JJ, Schüth F (2008) Surface and pore structure modification of ordered mesoporous carbons via a chemical oxidation approach. Microporous Mesoporous Mater 108:266-275

Beck JS, Vartuli JC, Roth WJ, Leonowicz ME, Kresge CT, Schmitt KD, Chu CTW, Olson DH, Sheppard EW, McCullen SB, Higgins JB, Schlenker JL (1992) A new family of mesoporous molecular sieves prepared with liquid crystal templates. J Am Chem Soc 114:10834-10843

Bhatti MS, Reddy AS, Thukral AK (2009) Electrocoagulation removal of $\mathrm{Cr}(\mathrm{VI})$ from simulated wastewater using response surface methodology. J Hazard Mater 172:839-846

Cheng Q, Li C, Xu L, Li J, Zhai M (2011) Adsorption of Cr(VI) ions using the amphiphilic gels based on 2-(dimethylamino)ethyl methacrylate modified with 1-bromoalkanes. Chem Eng J 173:42-48

Deng B, Alan TS (1996) Surface-catalyzed chromium(VI) reduction: reactivity comparisons of different organic reductants and different oxide surfaces. Environ Sci Technol 30:2484-2494

Diaz CEB, Lugo VL, Bilyeu B (2012) A review of chemical, electrochemical and biological methods for aqueous $\mathrm{Cr}(\mathrm{VI})$ reduction. J Hazard Mater 223-224:1-12

Donmez G, Aksu Z (2002) Removal of chromium(VI) from saline wastewaters by Dunaliella species. Process Biochem 38:751-762

Freundlich HMF (1906) Uber die adsorption in losungen. Z Phys Chem 57A:385-470

Ho YS, McKay G (1999) Pseudo-second order model for sorption processes. Process Biochem 34(5):451-465

HosseiniAsl SM, Ahmadi M, Ghiasvand M, Tardast A, Katal R (2013) Artificial neural network (ANN) approach for modeling of $\mathrm{Cr}(\mathrm{VI})$ adsorption from aqueous solution by zeolite prepared from raw fly ash (ZFA). J Ind Eng Chem 19:1044-1055

Huang J, Zhang X, Bai L, Yuan S (2012) Polyphenylene sulfide based anion exchange fiber: synthesis, characterization and adsorption of Cr(VI). J Environ Sci 24:1433-1438

Jun S, Joo SH, Ryoo R, Kruk M, Jaroniec M, Liu Z, Ohsuna T, Terasaki O (2000) Synthesis of new nanoporous carbon with hexagonally ordered mesostructure. J Am Chem Soc 122:10712-10713

Kresge CT, Leonowicz ME, Roth WJ, Vartuli JC, Beck JS (1992) Ordered mesoporous molecular sieves synthesized by a liquidcrystal template mechanism. Nature 359:710-712

Langmuir I (1916) The constitution and fundamental properties of solids and liquids. J Am Chem Soc 38(11):2221-2295

Li Q, Sun L, Zhang Y, Qian Y, Zhai J (2011) Characteristics of equilibrium, kinetics studies for adsorption of $\mathrm{Hg}(\mathrm{II})$ and $\mathrm{Cr}(\mathrm{VI})$ by polyaniline/humic acid composite. Desalination 266:188-194

Li Y, Zhu S, Liu Q, Chen Z, Gu J, Zhu C, Lu T, Zhang D, Ma J (2013) $\mathrm{N}$-doped porous carbon with magnetic particles formed in situ for enhanced $\mathrm{Cr}(\mathrm{VI})$ removal. Water Res 47(12):4188-4197

Liu W, Zhang L, Zhang C, Ren L (2012) Preparation and evaluation of activated carbon-based iron-containing adsorbents for enhanced $\mathrm{Cr}(\mathrm{VI})$ removal: mechanism study. Chem Eng J 189-190:295-302

Malik PK (2003) Dye removal from wastewater using activated carbon developed from sawdust. Dyes Pigm 56:239-249

Mitra P, Sarkar D, Chakrabarti S, Dutta BK (2011) Reduction of hexa-valent chromium with zero-valent iron: batch kinetic studies and rate model. Chem Eng J 171:54-60 
Olmez T (2009) The optimization of $\mathrm{Cr}(\mathrm{VI})$ reduction and removal by electrocoagulation using response surface methodology. J Hazard Mater 162:1371-1378

Ozdemir E, Duranŏglu D, Beker U, Avcı AO (2011) Process optimization for $\mathrm{Cr}(\mathrm{VI})$ adsorption onto activated carbons by experimental design. Chem Eng J 172:207-218

Robinson T, Chandran B, Nigam P (2002) Effect of pretreatments of three waste residues, wheat straw, corncobs and barely husks on dye adsorption. Bioresour Technol 85:119-124

Ryoo R, Joo SH, Jun S (1999) Synthesis of highly ordered carbon molecular sieves via template-mediated structural transformation. J Phys Chem B 103:7745-7746

Saeed A, Iqbal M (2003) Bioremoval of cadmium from aqueous solution by black gram husk (Cicerarientinum). Water Res 37:3472-3480

Shao Y, Wang L, Zhang J, Anpo M (2005) Synthesis of hydrothermally stable and long-range ordered Ce-MCM-48 and Fe-MCM48 materials. J Phys Chem B 109(44):20835-20841

Tang WQ, Zeng RY, Feng YL, Li XM, Zhen W (2013) Removal of $\mathrm{Cr}(\mathrm{VI})$ from aqueous solution by nano-carbonate hydroxylapatite of different $\mathrm{Ca} / \mathrm{P}$ molar ratios. Chem Eng J 223:340-346
Wang XS, Chen LF, Li FY, Chen KL, Wan WY, Tang YJ (2010) Removal of $\mathrm{Cr}(\mathrm{VI})$ with wheat-residue derived black carbon: reaction mechanism and adsorption performance. J Hazard Mater 175:816-822

Wang X, Liu J, Xu W (2012) One-step hydrothermal preparation of amino-functionalized carbon spheres at low temperature and their enhanced adsorption performance towards $\mathrm{Cr}(\mathrm{VI})$ for water purification. Colloids Surf A 415:288-294

Xi X, Guo X (2013) Preparation of bio-charcoal from sewage sludge and its performance on removal of $\mathrm{Cr}(\mathrm{VI})$ from aqueous solutions. J Mol Liq 183:26-30

Yoon J, Amy G, Chung J, Sohn J, Yoon Y (2009) Removal of toxic ions (chromate, arsenate, and perchlorate) using reverse osmosis, nanofiltration, and ultrafiltration membranes. Chemosphere 77:228-235

Zhao Y, Yang Sh, Ding D, Chen J, Yang Y, Lei Z, Feng Ch, Zhang Z (2013) Effective adsorption of $\mathrm{Cr}(\mathrm{VI})$ from aqueous solution using natural Akadama clay. $\mathbf{J}$ Colloid Interface Sci 395:198-204 